University of Wollongong

Research Online

Australian Institute for Innovative Materials -

Papers

Australian Institute for Innovative Materials

$1-1-2018$

The Precipitation Behavior and Hot Deformation Characteristics of Electron Beam Smelted Inconel 740 Superalloy

Xiaogang You

Dalian University of Technology

Yi Tan

Dalian University of Technology

Chang Wu

University of Wollongong, cw085@uowmail.edu.au

Qifan You

Dalian University of Technology

Longhai Zhao

Dalian University of Technology

See next page for additional authors

Follow this and additional works at: https://ro.uow.edu.au/aiimpapers

Part of the Engineering Commons, and the Physical Sciences and Mathematics Commons

Research Online is the open access institutional repository for the University of Wollongong. For further information contact the UOW Library: research-pubs@uow.edu.au 


\title{
The Precipitation Behavior and Hot Deformation Characteristics of Electron Beam Smelted Inconel 740 Superalloy
}

\author{
Abstract \\ The Inconel 740 superalloy was prepared by the electron beam smelting (EBS) technology, the \\ precipitation behavior and strengthening mechanism were studied, and the hot deformation \\ characteristics of EBS 740 superalloy were investigated. The results indicate that the EBS 740 superalloy \\ is mainly strengthened by the mechanism of weakly coupled dislocation shearing, and the resulting \\ critical shear stress is calculated to be $234.6 \mathrm{MPa}$. The deformation parameters show a great influence \\ on the flow behavior of EBS 740 superalloy. The strain rate sensitivity exponent increases with the \\ increasing of deformation temperature, and the strain hardening exponent shows a decreasing trend with \\ the increasing of strain. The activation energy of EBS 740 above $800^{\circ} \mathrm{C}$ is measured to be $408.43 \mathrm{~kJ} / \mathrm{mol}$, \\ which is higher than the $740 \mathrm{H}$ superalloy. A hyperbolic-sine-type relationship can be observed between \\ the peak stress and Zener-Hollomon parameter. Nevertheless, the influence of deformation parameters is \\ found to be considerably different at temperatures below and above $800{ }^{\circ} \mathrm{C}$. The size of dynamic \\ recrystallization (DRX) grains decreases with the increasing of strain rate when the strain rate is lower \\ than $1 / \mathrm{s}$, and reverse law can be found at higher strain rate. As a result, a piecewise function is \\ established between the DRX grain size and hot working parameters.

\section{Disciplines} \\ Engineering | Physical Sciences and Mathematics

\section{Publication Details} \\ You, X., Tan, Y., Wu, C., You, Q., Zhao, L. \& Li, J. (2018). The Precipitation Behavior and Hot Deformation \\ Characteristics of Electron Beam Smelted Inconel 740 Superalloy. Journal of Materials Engineering and \\ Performance, 27 (4), 1580-1591.
}

\section{Authors}

Xiaogang You, Yi Tan, Chang Wu, Qifan You, Longhai Zhao, and Jiayan Li 
The precipitation behavior and hot deformation characteristics of electron

\author{
beam smelted Inconel 740 superalloy \\ Xiaogang You ${ }^{\mathrm{a}, \mathrm{b}, \mathrm{c}}$, Yi Tan ${ }^{\mathrm{a}, \mathrm{b}, *}$, Chang Wu $\mathrm{u}^{\mathrm{d}}$, Qifan You ${ }^{\mathrm{a}, \mathrm{b}}$, Longhai Zhao ${ }^{\mathrm{a}, \mathrm{b}}$, Jiayan $\mathrm{Li}^{\mathrm{a}, \mathrm{b}}$ \\ ${ }^{a}$ School of Materials Science and Engineering, Dalian University of Technology, Dalian 116023, China \\ ${ }^{b}$ Laboratory for New Energy Material Energetic Beam Metallurgical Equipment Engineering of \\ Liaoning Province, Dalian 116024, China \\ ${ }^{c}$ Department of Metallurgy and Ceramics Science, Graduate School of Science and Engineering, Tokyo \\ Institute of Technology, 2-12-1, Ookayama, Meguro-ku, Tokyo, 152-8552, Japan \\ ${ }^{\mathrm{d}}$ Institute for Superconducting and Electronic Materials, University of Wollongong, Wollongong 2500, \\ Australia \\ *Corresponding author at: School of Materials Science and Engineering, Dalian University of \\ Technology, No. 2 Linggong Road, Ganjingzi District, Dalian 116023, China. Tel.: +86 41184707583 \\ Contact email address: tanyi@,dlut.edu.cn
} (Submitted May 9, 2017; in revised form November 14, 2017)

Materials Characterization JMEP-17-05-12979

\begin{abstract}
The Inconel 740 superalloy was prepared by the electron beam smelting (EBS) technology, the precipitation behavior and strengthening mechanism were studied, and the hot deformation characteristics of EBS 740 superalloy were investigated. The results indicate that the EBS 740 superalloy is mainly strengthened by the mechanism of weakly coupled dislocation (WCD) shearing, and the resulting critical shear stress is calculated to be $234.6 \mathrm{MPa}$. The deformation parameters show a great influence on the flow behavior of EBS 740 superalloy. The strain rate sensitivity exponent increases with the increasing of deformation temperature, and the strain hardening exponent shows a decreasing trend with the increasing of strain. The activation energy of EBS 740 above $800{ }^{\circ} \mathrm{C}$ is measured to be $408.43 \mathrm{~kJ} / \mathrm{mol}$, which is higher than the $740 \mathrm{H}$ superalloy. A hyperbolic-sine type relationship can be observed between the peak stress and Zener-Hollomon parameter. Nevertheless, the influence of deformation parameters is found to be considerably different at temperatures below and above $800^{\circ} \mathrm{C}$. The size of dynamic recrystallization (DRX) grains decreases with the increasing of strain rate when the strain rate is lower than $1 / \mathrm{s}$, and reverse law can be found at higher strain rate. As a result, a piecewise function is established between the DRX grain size and hot working parameters.
\end{abstract}

Keywords: Precipitation; Hot deformation; Electron beam smelting; 740 superalloy

\title{
1. Introduction
}

The Inconel 740 superalloy is a $\gamma^{\prime}$ strengthened nickel based superalloy developed by the Special Metals Corporation, and is used to fabricate the ultra-supercritical boiler tubes. It was designed to own a good creep strength at temperatures up to $750{ }^{\circ} \mathrm{C}\left(100 \mathrm{MPa} / 10^{5} \mathrm{~h}\right)$ together with a good corrosion resistance during the long term operation[1]. The high temperature strength of 740 superalloy is 
provided by the substantial precipitation of $\gamma^{\prime}-\mathrm{Ni}_{3}(\mathrm{Al}, \mathrm{Ti})$ phase and solid solution strengthening of $\mathrm{Co}, \mathrm{Cr}, \mathrm{Fe}$, and Mo atoms. Besides, the formation of carbides such as $\mathrm{TiC}$ and $\mathrm{Cr}_{23} \mathrm{C}_{6}$ can further strengthen the superalloy by retarding the grain boundary sliding[2,3]. Moreover, the $\mathrm{Ti}, \mathrm{Al}$ and $\mathrm{Cr}$ elements could provide the good corrosion resistance by formation of the three distinct oxidation layers for 740 superalloy[4].

The Inconel 740 superalloy is commonly prepared by vacuum induction melting (VIM) or a combination of VIM plus vacuum arc remelting (VAR) or electroslag remelting (ESR). In this work, the 740 superalloy was prepared employing the electron beam smelting (EBS) technology. Compared with the traditional method, the EBS technology shows several advantages such as the better removal of non-metallic and volatile impurities, and the good control of energy distribution to acquire ingot with excellent metallurgical quality[5]. Besides, the super-clean alloy free of inclusions could be obtained by using the water-cooled copper crucible, which could also lower the costs of production. As a wrought nickel based superalloy, the deformation parameters of Inconel 740 superalloy are rather important during the forging process, which can be adjusted to obtain optimized microstructures and excellent properties. It is known that the processing parameters such as temperature, strain rate and strain show a great influence on the hot working behavior of wrought superalloys[6,7]. Besides, the $\gamma^{\prime}$ precipitates in the matrix can influence the hot workability of $\gamma^{\prime}$ strengthened superalloys as well. Nevertheless, no detail descriptions about the influence of hot working parameters on the strain rate sensitivity exponent and strain hardening exponent as well as the dynamic crystallization behavior of Inconel 740 superalloys has been found in the open literature. As a result, it is quite necessary to investigate the hot deformation behavior of the 740 superalloy at lower and elevated temperatures.

In this paper, the Inconel 740 superalloy is prepared by the electron beam smelting technology. The strain rate sensitivity exponent and strain hardening exponent for the electron beam smelted Inconel 740 at various temperatures and strains are calculated. The dependence of flow behavior and microstructural evolution on deformation temperature and strain rate is established by introducing the Zener-Hollomon parameter. The effect of deformation parameters on the peak stress and dynamic recrystallization behavior are analyzed.

\section{Materials and methods}

\subsection{Materials and heat treatment}

The raw materials for preparation of Inconel 740 were simple substances. The purity of each element and the smelting parameters were described in reference [2]. The chemical composition (wt.\%) of the EBS 740 ingot is tested by the X-ray fluorescence (XRF) spectrometry. The sample for XRF detection was cut to a cylinder with diameter of $30 \mathrm{~mm}$, and the surface layer was ground and mechanically polished. The compositions are as follows: $\mathrm{Ni}, 47.16 ; \mathrm{Cr}, 25.98$; $\mathrm{Co}, 20.70 ; \mathrm{Nb}, 2.23$; $\mathrm{Ti}, 1.76$; $\mathrm{Fe}, 0.84 ; \mathrm{Mo}, 0.56 ; \mathrm{Al}, 0.45 ; \mathrm{Si}, 0.21 ; \mathrm{Mn}, 0.11$. After the smelting process, the ingot was homogenized and subsequently isothermally forged at $1177^{\circ} \mathrm{C}$ followed by air cooling. Samples were cut from the forged bars, and solution treated at $1150{ }^{\circ} \mathrm{C}$ for 30 
min and aged at $800{ }^{\circ} \mathrm{C}$ for $16 \mathrm{~h}$.

\subsection{The compression tests at room and elevated temperatures}

The compression tests were conducted on a Gleeble 1500 thermo-mechanical simulator, with the sample size of $5 \mathrm{~mm}$ in diameter and $10 \mathrm{~mm}$ in height. The aged samples were compressed at $538^{\circ} \mathrm{C}, 649{ }^{\circ} \mathrm{C}, 760{ }^{\circ} \mathrm{C}, 800{ }^{\circ} \mathrm{C}, 1050{ }^{\circ} \mathrm{C}$ and $1150{ }^{\circ} \mathrm{C}$, respectively, with strain rates of $0.1 / \mathrm{s}, 1 / \mathrm{s}$ and $10 / \mathrm{s}$ to reveal the hot compression behavior of EBS 740 superalloy.

\subsection{Metallographic preparation}

Samples for metallographic and SEM observation were mechanically polished and etched with a solution composed of $4 \mathrm{~g} \mathrm{CuSO}_{4}, 1 \mathrm{ml} \mathrm{H}_{2} \mathrm{SO}_{4}, 20 \mathrm{ml} \mathrm{HCl}$ and 16 $\mathrm{ml} \mathrm{H}_{2} \mathrm{O}$. The SEM experiment was conducted on a Supra55 field emission electronic microscope. The accelerating voltage is $15 \mathrm{kV}$ and working distance is approximately $17 \mathrm{~mm}$. The X-ray diffraction technique was employed on a Panalytical Empyrean diffractometer. The scanning step size and speed are $0.02^{\circ}$ and $2.00^{\circ} / \mathrm{min}$, respectively. The TEM experiment was conducted on a Tecnai G220 S-Twin electron microscope. The samples were mechanically thinned down to a thickness of $20 \sim 40 \mu \mathrm{m}$, and then were thinned by argon ion beam to acquire thin areas with thickness of several nanometers. The grain size of EBS 740 superalloy was calculated by the intercept method, and the size and volume fraction of the $\gamma^{\prime}$ precipitates were determined by using the Image-Pro Plus software and the method of quantification metallographic analysis.

\section{Results and discussion}

\subsection{Microstructures and precipitation behavior of EBS 740 superalloy}

The microstructure of EBS 740 superalloy after aging treatment is composed of equiaxed grains. The average grain size is approximately $74.15 \mu \mathrm{m}$ with a standard deviation of $7.33 \mu \mathrm{m}$, and substantial annealing twins have been also observed, as shown in Fig. 1(a). In the SEM secondary electron morphology, the dispersively distributed $\gamma^{\prime}$ precipitates can be clearly observed. The size and volume fraction of $\gamma^{\prime}$ precipitates are determined to be approximately $28.85 \mathrm{~nm}(\mathrm{STDEV}=2.38 \mathrm{~nm})$ and $37.32 \%$, respectively, by further quantification metallographic analysis of TEM images employing the Image-Pro Plus software.

In the superalloys which are strengthened by the precipitation phase, there exist two mechanisms when the dislocation movement is resisted, namely the particle shearing and Orowan looping mechanism. The shearing mechanism works when the precipitates are small and coherent, while larger and coherent precipitates are applicable to Orowan mechanism. It is well established in the research work of L.M. Brown and $\mathrm{W}$. Huther that the shearing mechanism is consisted of the strongly coupled dislocation (SCD) model and weakly coupled dislocation (WCD) model[8,9]. The critical shear stress $\tau$ for the three mechanisms can be expressed as follows:

$$
\tau_{p s m, W C D}=\frac{1}{2}\left(\frac{\gamma_{A P B}}{b}\right)^{\frac{3}{2}}\left(\frac{b d f}{T}\right)^{\frac{1}{2}} A-\frac{1}{2}\left(\frac{\gamma_{A P B}}{b}\right) f
$$




$$
\begin{gathered}
\tau_{p s m, \mathrm{SCD}}=\left(\frac{\sqrt{3}}{2}\right) \frac{T f^{\frac{1}{2}} w}{b d}\left(1.28 \frac{d \gamma_{A P B}}{w T}-1\right)^{\frac{1}{2}} \\
\tau_{p s m, \text { looping }}=\alpha G b \frac{f}{d(1-f)}
\end{gathered}
$$

where $\gamma_{A P B}$ stands for the antiphase boundary energy, whose value is $0.28 \mathrm{~J} / \mathrm{m}^{2}$ referring to M.P. Jackson et al.[10]; $d$ stands for the mean particle diameter; $b$ is the value of Burgers Vector; $f$ is the volume fraction of the $\gamma^{\prime}$ phase; $\mathrm{A}$ is the numerical factor which depends on the morphology of the particles, whose value is 0.72 in the research; $T$ is the line tension of dislocations, and its value can be evaluated as $0.5 G b^{2}$ ( $G$ represents the shear modulus); $w$ is a constant that accounts for the elastic repulsion between the strong coupled dislocations, whose value can be estimated as $1[11]$; $\alpha$ is a fitting parameter, whose value is 1.5 . The shear modulus $G$ of the EBS 740 superalloy is calculated as $80.17 \mathrm{GPa}$, and the Burger's vector is calculated to be $0.253 \mathrm{~nm}$. The critical shear stress caused by the three mechanisms with the increasing of particle size is shown in Fig. 2(a). The CRSS value increases with the increasing of precipitate diameter for WCD model, and decreases for SCD and Orowan mechanism. It can be concluded from Fig. 2(a) that when the particle size is less than $39 \mathrm{~nm}$, the WCD model is determined to be the decisive mechanism for precipitation strengthening. When the size of the particle is between $39 \mathrm{~nm}$ and 99.6 $\mathrm{nm}$, the SCD model will work. Further increasing of precipitate size gives rise to the Orowan looping of dislocations. The diameter of $\gamma^{\prime}$ precipitates in EBS 740 is determined to be approximately $30 \mathrm{~nm}$, which is also illustrated in Fig. 1(b), and thus the WCD shearing is expected for the strengthening of EBS 740. In addition to the mechanism of shearing, the modulus hardening mechanism contributes to the strengthening behavior of EBS 740 according to A.J. Ardell[12]. The shear stress caused by modulus hardening is given as:

$$
\tau_{m h}=0.9(R f)^{1 / 2} \frac{T}{b}\left(\frac{\Delta G}{G}\right)^{3 / 2}\left[2 b \ln \left(2 R / f^{1 / 2} b\right)\right]^{-3 / 2}
$$

in which $R$ denotes the radius of $\gamma^{\prime}$, and $\Delta G$ denotes the shear modulus difference of the matrix and precipitates. The shear modulus of $\gamma^{\prime}$ is determined to be $72.87 \mathrm{GPa}$. Consequently, the strengthening effects of WCD model and modulus hardening in relation with the volume fraction and size of $\gamma^{\prime}$ are illustrated in Fig. 2(b) and (c), respectively. The critical shear stress (CRSS) caused by WCD shearing and modulus hardening are calculated as $234.60 \mathrm{MPa}$ and $142.39 \mathrm{MPa}$. As a result, the strengthening effect is measured to be approximately $652.95 \mathrm{MPa}$ according to the relationship between the normal stress and critical shear stress which is well established in [13]. The calculated yield stress attributed to the precipitation strengthening effect of gamma prime phase matches well with the experimental results, in which the yield stress $(0.2 \%$ offset $)$ of the solution treated and aged EBS 740 superalloys with the strain rate of $0.1 / \mathrm{s}$ at room temperature are measured to be 262.4 MPa and 889.0 MPa, respectively. 


\subsection{Flow stress of EBS 740 superalloy}

Fig. 3 presents the true stress-strain curves of the standard heat treated EBS 740 superalloy compressed at lower and higher temperatures with strain rate from $0.1 / \mathrm{s}$ to $10 / \mathrm{s}$. It is clear that both the peak stress and compression strength decrease with the increasing of deformation temperature at a certain strain rate. Besides, the effect of deformation temperature is much more obvious at higher deformation temperature. However, the effect of strain rate on the peak stress is various at different deformation temperatures. When deformed at temperatures higher than $800{ }^{\circ} \mathrm{C}$, the peak stress increases with the strain rate, which is similar with the general results, as reported by Hongbin Zhang et. al[14]. When the deformation temperature is lower than $800{ }^{\circ} \mathrm{C}$, it seems that the peak stress is higher at lower strain rate. The phenomenon is novel since the dynamic recovery process is not evident at lower deformation temperature.

\section{Strain rate sensitivity exponent}

The strain rate sensitivity exponent is a measurement of the way the stress on a material reacts to changes in strain rate, and could be calculated by the following equation[15]:

$$
m=\left.\frac{d \ln \sigma}{d \ln \dot{\varepsilon}}\right|_{\varepsilon, T}
$$

where $\sigma$ is the flow stress; $\dot{\varepsilon}$ is the strain rate; $\varepsilon$ is the strain; $T$ denotes the absolute temperature. It can be seen from Fig. 4(a) that the strain rate sensitivity exponent increases with the increasing of deformation temperature when the strain rate is 0.5 . Nevertheless, compared with the deformation at high temperatures, the strain rate sensitivity exponent becomes negative at lower deformation temperatures. The phenomenon indicates a coexistence of the Portevin-Le Chatelier (PLC) effect and relatively inhomogeneous deformation at temperatures lower than $800{ }^{\circ} \mathrm{C}[16]$.

The variation of strain rate sensitivity exponent with strain at deformation temperature of $538{ }^{\circ} \mathrm{C}$ and $1050{ }^{\circ} \mathrm{C}$ is shown in Fig. 4(b). It can be seen that the variation of strain rate sensitivity exponent shows similar characteristics with the flow stress-strain curve when deformed at $1050{ }^{\circ} \mathrm{C}$. The strain rate sensitivity exponent decreases firstly at lower strain, and then increases significantly at higher strain, and finally become stable. The strain rate sensitivity exponent represents the capacity of material to resist necking and influence the overall deformation stability in high temperature deformation[17]. It is usually believed that the variation of strain rate sensitivity with strain is affected by three mechanisms, namely the work hardening arised from the dislocation accumulation and interaction among dislocations, the thermal softening effect related to the dislocation annihilation, and the microstructure evolution[18]. In the early stage of deformation, the density of dislocations increases with the increasing of strain. The aggregation of dislocations would give rise to the stress concentration, which could degrade the stability of high temperature deformation, thus the strain rate sensitivity exponent decreases. With the further deformation of EBS 740 superalloy at higher temperatures, the accumulation of 
dislocations in the grain and at the phase boundaries promotes the nucleation of DRX grains, and the strain rate sensitivity exponent increases. During the terminal stages of deformation, a balance could be reached with the mutual effect of hardening and dynamic softening, namely dynamic recovery and dynamic recrystallization, thus the third stage could be expected. Compared with the deformation at $1050{ }^{\circ} \mathrm{C}$, it is interestingly found that the values of strain rate sensitivity exponent are negative when deformed at $538{ }^{\circ} \mathrm{C}$. Besides, with the increasing of strain, the $m$ value increases dramatically firstly and then keeps almost constant at strain greater than 0.12 . The phenomenon of negative stain sensitivity (NSRS) has been reported in a number of nanostructured or aluminum alloys, which is considered to be caused by the interactions between dislocations and solutes or precipitates[19,20]. The smaller strain rate sensitivity exponent value at lower strain is connected with the higher degree of inhomogeneous deformation. Nevertheless, the degree of inhomogeneous deformation is alleviated with the deformation going on, and results in a stable strain rate sensitivity of about -0.02 .

\subsection{Strain hardening exponent}

The strain hardening exponent is an important factor in characterization of the ability of deformation resistance, which results from a balance between the hardening mechanism and softening mechanism. The strain hardening exponent $n$ could be calculated in the following form[21]:

$$
n=\left.\frac{d \log \sigma}{d \log \varepsilon}\right|_{\varepsilon, T}
$$

The variables in equation (6) are the same as described in equation (5). The variation of strain hardening exponent with strain at various strain rates and deformation temperatures can be seen in Fig. 5. When deformed at lower temperature, the value of $n$ decreases with the increasing of strain. Similar decreasing trend can be observed for various strain rates, as shown in Fig. 5(a). The strain hardening exponent with lower strain rate is greater than that with higher strain rate, which could arise from the more homogeneous deformation and stable dislocation shearing and breaking-free process. When deformed at higher temperature, the value of $n$ decreases gradually with strain and reaches a negative value at a strain of approximately 0.3 . However, the strain rate influences the strain hardening exponent significantly. The value of $n$ is much bigger at lower strain with the strain rate of $10 / \mathrm{s}$, and much smaller when the strain is higher than 0.4. It can be concluded that softening mechanism become more obvious with the increasing of strain, which is similar with the research work of K. Wang et. al[17], in which the softening is considered as the critical mechanism during isothermal compression with lower strain at higher deformation temperature. The softening mechanism can be also discovered in the flow stress-strain results that the stress reaches a peak value firstly, and then decreases with the increasing of the strain. Besides, it can also be found in Fig. 3 that the flow stress reaches its peak value at a lower strain when deformed at higher temperature. The more notable softening effect at higher strain rate could be considered that the increasing of strain rate accelerates the dislocation movement, and the accumulation of dislocations could cause the 
nucleation of the DRX grains. The dynamic crystallization behavior at different strain rates has also been verified in our previous research work[3].

\subsection{Constitutive analysis for EBS 740 superalloy}

\subsubsection{The calculation of activation energy}

The rheological behavior of electron beam smelted 740 superalloy during hot deformation can be described by the following equations[22]:

$$
\begin{gathered}
\dot{\varepsilon} \exp \left(\frac{Q}{R T}\right)=A_{1} \sigma_{p}^{n} \\
\dot{\varepsilon} \exp \left(\frac{Q}{R T}\right)=A_{2} \exp \left(\beta \sigma_{p}\right)
\end{gathered}
$$

where $A_{1}$ and $A_{2}$ are structural factors; $n$ stands for the stress exponent; $\sigma_{p}$ represents the peak stress; $\beta$ is a constant. The value of $\beta, A_{1}, A_{2}$ and $n$ ' are constant which are independent of temperature. The equation (7) is applicable at a lower stress level, namely at higher deformation temperature, while equation (8) is applicable in the opposite situation. The equation (7) and (8) can be transformed into the following formulas when the logarithm is applied on both sides:

$$
\begin{aligned}
& \ln \dot{\varepsilon}=\ln A_{1}+n \ln \sigma_{p}-Q / R T \\
& \ln \dot{\varepsilon}=\ln A_{2}+\beta \sigma_{p}-Q / R T
\end{aligned}
$$

As a result, the value of $n$ ' and $\beta$ above $800{ }^{\circ} \mathrm{C}$ can be calculated combining with the fitting results in Fig. 6(a), whose value are determined to be 5.2590 and 0.0199 , respectively.

According to the model well established by Sellars and Tegart, a more general form was introduced, which was suitable for a wide stress range. It can be expressed as[23]:

$$
\dot{\varepsilon}=A[\sinh (\alpha \sigma)]^{n} \exp \left(\frac{-Q}{R T}\right)
$$

where $A$ is a constant; $\alpha$ is the value of $\beta / n ; Q$ denotes the deformation activation energy of high temperature; $R$ is the gas constant. The formula can be described as follows to obviously observe the relationship between the peak stress, strain rate and deformation temperature:

$$
\ln [\sinh (\alpha \sigma)]=\frac{1}{n} \ln \dot{\varepsilon}+Q / n R T-\frac{1}{n} \ln A
$$

The relationship between $\ln \dot{\varepsilon}$ and $\ln \sinh (\alpha \sigma)$ is shown in Fig. 6(b), thus the average value of $n$ is calculated to be 4.373 by linear fitting. The relationship between $\ln \sinh (\alpha \sigma)$ and $1 / T$ at a constant stain rate is shown in Fig. 6(c). Consequently, the deformation activation energy for EBS 740 superalloy above $800{ }^{\circ} \mathrm{C}$ is determined to be $408.43 \mathrm{~kJ} / \mathrm{mol}$. The similar method can be applied to calculate the deformation activation energy at lower temperatures. The value of $n, \beta, \alpha, n$ and $Q$ are calculated 
to be $149.1467,0.1431,9.5921 \times 10^{-4}, 112.5704$, and $539.24 \mathrm{~kJ} / \mathrm{mol}$, respectively. The separating of the data into lower and higher deformation temperature rages has been also reported in reference [24], which allows a more accurate evaluation of activation energy.

It is well established in the research work of Y. Liu that the activation energy is an exponential function of the content of alloy elements[25]. According to the model presented by Bi[26], the activation energy of EBS 740 is calculated. The experimental and calculated activation energy of EBS 740 are shown in Tab. 1 and compared with other superalloys. As can be concluded from Tab. 1 that the activation energy of EBS 740 superalloy at high temperatures is much higher than both $740 \mathrm{H}$ and 690 alloy, and even comparable with Inconel 718 who is strengthened by $\mathrm{L}_{2}$ ordered face centered cubic (FCC) $\gamma^{\prime}$ phase and body centered tetragonal (BCT) structured $\gamma^{\prime \prime}$ precipitates. The experimental value of $Q$ for EBS 740 superalloy is larger than the calculated value. The first reason is the effect of Co element is neglected according to the model of $\mathrm{Bi}$ et. al., the other is arised from the dispersively distribution of $\gamma$ precipitates in the matrix.

\subsubsection{The relationship between the peak stress and Zener-Hollomon parameter}

The Zener-Hollomon parameter is also called the temperature modified strain rate, which is defined as[27]:

$$
Z=\dot{\varepsilon} \exp (Q / R T)=A[\sinh (\alpha \sigma)]^{n}
$$

The relationship between the peak stress and Zener-Hollomon parameter can be plotted from Eq. (13), as shown in Fig. 7. It can be observed that the hyperbolic-sine function obeys a good linear fit with the logarithmic value of $Z$ for both higher and lower deformation temperatures. Nevertheless, the deformation behavior at lower temperature is obviously different from that at higher deformation temperature. The relationship between the peak stress and the Zener-Hollomon parameter can be expressed as follows:

$$
\begin{array}{cc}
\sigma_{p}=264.27 \sinh ^{-1}\left(3.24 \times 10^{-4} Z^{0.23}\right) & \left(T>800^{\circ} \mathrm{C}\right) \\
\sigma_{p}=1042.52 \sinh ^{-1}\left(0.62 Z^{0.0099}\right) & \left(T \leq 800^{\circ} \mathrm{C}\right)
\end{array}
$$

The peak stress at lower deformation temperatures are much higher compared with that deformed at temperatures higher than $800{ }^{\circ} \mathrm{C}$. The phenomenon is attributed to the fact that the rearrangement of dislocations, namely dynamic recovery is restrained at lower deformation temperature, especially in superalloys with low stacking fault energy.

\subsubsection{The relationship between the Zener-Hollomon parameters and grain size}

The relationship between the Zener-Hollomon parameter and the grain size of dynamic recrystallization (DRX) grains can be described by the following power-law equation:

$$
D=B \cdot Z^{k}
$$

in which $k$ is usually chosen as a negative value, which means the size of DRX grains 
decreases with strain rate and increases with the deformation temperature[28]. The optical microstructures of EBS 740 superalloys deformed to a strain of 0.7 at various temperatures with different strain rates and subsequently quenched are shown in Fig. 8. The variation of DRX grain size with temperature and strain rate for EBS 740 superalloy is shown in Tab. 2. When the strain rate is lower than 1.0/s, the DRX grain size increases with deformation temperature and decreases with strain rate. Nevertheless, the DRX grain size increases with the increasing of strain rate and deformation temperature when the strain rate is greater than 1.0/s. Similar results are observed in the research work of Wang that the strain rate plays opposite roles under different ranges for the DRX grain size[29]. The relationship between the deformation parameters and DRX grain size can be expressed as a piecewise function as follows at different strain rates:

$$
\begin{gathered}
D=B_{1} Z^{k_{1}} \quad(\dot{\varepsilon}<1) \\
D=B_{2}(\dot{\varepsilon})^{K_{2}} \exp (Q / R T) \quad(\dot{\varepsilon} \geq 1)
\end{gathered}
$$

where $B_{1}, B_{2}, k_{1}, k_{2}$ are constant values, and $Q^{`}$ represents the value of $-k_{2} \cdot Q$. The relationship between the DRX grain size and hot working parameters is plotted in Fig. 9. As a result, the value of $B_{1}, B_{2}, k_{1}$, and $k_{2}$ can be calculated by the linear fitting results in Fig. 9. The piecewise function can be renewed as follows for the EBS 740 superalloy:

$$
\begin{array}{cc}
D=1088585.8 \cdot Z^{-0.1859} & (\dot{\varepsilon}=0.1) \\
D=15020.5 \dot{\varepsilon}^{0.0839} \exp (-34275.8 / R T) & (\dot{\varepsilon}=1) \\
D=1.852 \times 10^{6} \dot{ }^{0.1962} \exp (-80127.3 / R T) \quad(\dot{\varepsilon}=10)
\end{array}
$$

When the strain rate is lower than $1 / \mathrm{s}$, the increasing of strain rate accelerates the dislocation movement, and the accumulation of dislocations at the grain and phase boundaries could promote the nucleation of DRX grains. In the meantime, the decreasing of strain rate extends the deformation period, which facilitates the crystallization and grain growth. Nevertheless, when deformed with higher strain rate, a significant amount of adiabatic heating could be produced during the deformation. The temperature change due to adiabatic heating during compression at a high strain rate can be calculated by the following equations[29]:

$$
\Delta T=\eta \beta \frac{\sigma_{a v e} \Delta \varepsilon}{\rho c}
$$

where $\Delta T$ is the temperature variation; $\eta$ denotes the adiabatic factor, whose value is 1 when used on adiabatic conditions at rates $\geq 10 / \mathrm{s}[30] ; \beta$ is the ratio of mechanical work transformed into heat, referring to the value of 0.97 in reference [29]; $\Delta \varepsilon$ is the interval of strain; $\rho$ and $c$ are the density and specific heat; $\sigma_{\text {ave }}$ is the average stress in $\Delta \varepsilon$. The average stress can be calculated through the following equation: 


$$
\sigma_{\text {ave }}=\frac{1}{\Delta \varepsilon} \int_{\varepsilon_{0}}^{\varepsilon_{0}+\Delta \varepsilon} \sigma d \varepsilon
$$

The temperature increase by adiabatic heating at higher deformation temperature with strain rate of $10 / \mathrm{s}$ is shown in Tab. 3. It can be seen in the table that the temperature rise increases with the strain at a certain temperature, and decreases with the increasing of deformation temperatures.

The influence of the resulting adiabatic heating could be considered in the following two ways. The mobility of high angle grain boundary is much larger at higher strain rate according to the Arrhenius relationship. When the grain boundaries migrate faster than the development of interior substructure, the larger grain size could be discovered with the increasing of strain rate. The other effect is that the adiabatic heating could give rise to the solution of $\gamma^{\prime}$ precipitates, especially when the deformation temperature is higher than $800{ }^{\circ} \mathrm{C}$. The precipitation behavior of $\gamma^{\prime}$ phase deformed at $1050{ }^{\circ} \mathrm{C}$ and $1150{ }^{\circ} \mathrm{C}$ can be analyzed by separating the low angle diffraction peaks on (200) plane employing the Gaussian fitting method, as shown in Fig. 10. The precipitation behavior of $\gamma^{\prime}$ phase at strain rate of $0.1 / \mathrm{s}$ and $1 / \mathrm{s}$ are similar when deformed at $1050{ }^{\circ} \mathrm{C}$ and $1150{ }^{\circ} \mathrm{C}$. Nevertheless, when the strain rate is $10 / \mathrm{s}$, the ratio of $\gamma^{\prime} / \gamma$ decreases significantly compared with that deformed at lower strain rates. The reason is that the dissolution of $\gamma^{\prime}$ occurs due to the resulting adiabatic heating at higher strain rate. Consequently, the effect of $\gamma^{\prime}$ precipitates on promoting the grain nucleation and hindering the grain growth is weakened. The TEM microstructures before deformation and deformed at $1050{ }^{\circ} \mathrm{C}$ with strain rate of $10 / \mathrm{s}$ are shown in Fig. 11. The $\gamma^{`}$ precipitates with size of several nanometer can be clearly observed in the deformed microstructure, which is shown in Fig. 11(b). Nevertheless, the volume fraction and size of the $\gamma^{\prime}$ precipitates are much smaller compared with those before deformation. The morphology of $\gamma^{\prime}$ precipitates before deformation is shown in Fig. 11(a). Fig. 11(c) exhibits the morphology of DRX grains and sub-grain structure in a DRX grain. The substantial sub-grain structure can be also observed in Fig. 11(d), which means the dynamic recovery and dynamic recrystallization proceed simultaneously. It should be noted from Fig. 11(c) that the grains are preferred to nucleate around the $\gamma^{\prime}$ precipitates. The effect of $\gamma^{\prime}$ precipitate on grain nucleation and growth is also established in [31].

\section{Conclusions}

The electron beam smelting technology was employed to prepare the Inconel 740 superalloy, and the strengthening mechanism and deformation characteristics were investigated. From this work, the following conclusions can be drawn:

(1) The grain size of EBS 740 superalloy is about $74.15 \mu \mathrm{m}$, and the $\gamma^{\prime}$ precipitates with diameter of approximately $28.85 \mathrm{~nm}$ are dispersively distributed in the matrix. The EBS 740 superalloy is mainly strengthened by the mechanism of weakly coupled dislocation (WCD) shearing model, and the precipitation strengthening effect is measured to be approximately $652.95 \mathrm{MPa}$.

(2) The strain rate sensitivity exponent $m$ increases with the increasing of deformation 
temperature, and the variation of $m$ shows different characteristics with strain at lower and higher deformation temperatures. The strain hardening exponent shows a decreasing trend with the increasing of strain, which indicates an enhanced mechanism of softening with the increasing of strain.

(3) The activation energy of EBS 740 superalloy above and below $800{ }^{\circ} \mathrm{C}$ are measured to be 408.43 and $539.24 \mathrm{~kJ} / \mathrm{mol}$, respectively. The relationship between the peak stress and deformation parameters can be described by a piecewise hyperbolic-sine function as following:

$$
\begin{array}{cc}
\sigma_{p}=264.27 \sinh ^{-1}\left(3.24 \times 10^{-4} Z^{0.23}\right) & \left(T>800{ }^{\circ} \mathrm{C}\right) \\
\sigma_{p}=1042.52 \sinh ^{-1}\left(0.62 Z^{0.0099}\right) & \left(T \leq 800^{\circ} \mathrm{C}\right)
\end{array}
$$

(4) The size of dynamic recrystallization (DRX) grains decreases with the increasing of strain rate when the strain rate is lower than $1 / \mathrm{s}$, and reverse law can be found at higher strain rate. The dependence of DRX grain size on the deformation parameters is determined to be a piece wise exponential function at various strain rates.

\section{Acknowledgement}

The authors gratefully acknowledge financial support from the Specialized Research Fund for the National Key Research and Development Plan (Grant No. 2017YFA0403804).

\section{Reference}

[1] R. Viswanathan, K. Coleman, U. Rao, Materials for ultra-supercritical coal-fired power plant boilers, Int. J. Pres. Ves. Pip. 83 (2006) 778-783.

[2] X. You, Y. Tan, J. Li, P. Li, C. Dong, S. Shi, J. Liao, S. Qin, Effects of solution heat treatment on the microstructure and hardness of Inconel 740 superalloy prepared by electron beam smelting, J. Alloys Compd. 638 (2015) 239-248.

[3] Y. Tan, X. You, Q. You, J. Li, S. Shi, P. Li, Microstructure and deformation behavior of nickel based superalloy Inconel 740 prepared by electron beam smelting, Mater. Charact.114 (2016) 267-276.

[4] X. You, Y. Tan, Q. You, S. Shi, J. Li, F. Ye, X. Wei, Preparation of Inconel 740 superalloy by electron beam smelting, J. Alloys Compd. 676 (2016) 202-208.

[5] A. Choudhury, E. Hengsberger, Elerctron beam melting and refinining of metals and alloys, ISIJ Int. 32 (1992) 673-681.

[6] H. Yuan, W.C. Liu, Effect of the $\delta$ phase on the hot deformation behavior of Inconel 718, Mater. Sci. Eng. A 408 (2005) 281-289.

[7] A. Thomas, M. El-Wahabi, J.M. Cabrera, J.M. Prado, High temperature deformation of Inconel 718, J. Mater. Process. Technol. 177 (2006) 469-472.

[8] L.M. Brown, R.K. Ham, A. Kelly, R.B. Nicholson, Strengthening methods in crystals, Appl. Sci. Lond. (1971) 9.

[9] W. Huther, B. Reppich, Interaction of dislocations with coherent, stree-free ordered particles, 
Zeitschrift Fur Metallkunde 69 (1978) 628-634.

[10] M.P. Jackson, R.C. Reed, Heat treatment of UDIMET 720Li: the effect of microstructure on properties, Mater. Sci. Eng. A 259 (1999) 85-97.

[11] B. Reppich, Some new aspects concerning particle hardening mechanisms in $\gamma^{\prime}$ precipitating Ni-base alloys-I. Theoretical concept, Acta Metall. 30 (1982) 87-94.

[12] A.J. Ardell, Precipitation hardening, Metall. Trans. A 16 (1985) 2131-2165.

[13] J.H. Oh, B.G. Yoo, I.C. Choi, M.L. Santella, J.I. Jang, Influence of thermo-mechanical treatment on the precipitation strengthening behavior of Inconel 740, a Ni-based superalloy, J. Mater. Res. 26 (2011) 1253-1259.

[14] H. Zhang, K. Zhang, Z. Lu, C. Zhao, X. Yang, Hot deformation behavior and processing map of a $\gamma^{\prime}$-hardened nickel-based superalloy, Mater. Sci. Eng. A 604 (2014) 1-8.

[15] W.A. Backofen, I.R. Turner, D.H.Avery, Superplasticity in an Al-Zn alloy, Trans. ASM 57 (1964) 980-990.

[16] A. Van den Beukel, Theory of the effect of dynamic strain aging on mechanical properties, Phys. Status Solidi (a) 30 (1975) 197-206.

[17] K. Wang, M.Q. Li, J. Luo, C. Li, Effect of the $\delta$ phase on the deformation behavior in isothermal compression of superalloy GH4169, Mater. Sci. Eng. A 528 (2011) 4723-4731.

[18] J. Luo, M.Q. Li, Strain rate sensitivity and strain hardening exponent during the isothermal compression of Ti60 alloy, Mater. Sci. Eng. A 538 (2012) 156-163.

[19] Y.M. Wang, A.M. Hodge, P.M. Bythrow, T.W. Barbee Jr., A.V. Hamza, Negative strain rate sensitivity in ultrahigh-strength nanocrystalline tantalum, Appl. Phys. Lett. 89 (2006) 081903.

[20] B.Q. Han, J. Huang, Y.T. Zhu, E.J. Lavernia, Negative strain-rate sensitivity in a nanostructured aluminum alloy, Adv. Eng. Mater. 8 (2006) 945-947.

[21] J.H. Holloman, Tensile deformations, Trans. Met. Soc. AIME 162 (1945) 268-290.

[22] C.M. Sellars, W.J.M.G. Tegart, Relationship between strength and structure in deformation at elevated temperatures, Mem. Sci. Rev. Met. 63 (1966) 731.

[23] T.Sakai, Dynamic recrystallization microstructures under hot working conditions, J. Mater.Process. Tech. 53 (1995) 349-361.

[24] A. Chamanfar, M. Jahazi, J. Gholipour, P. Wanjara, S. Yue, Evolution of flow stress and microstructure during isothermal compression of Waspaloy, Mater. Sci. Eng. A 615 (2014) 497-510.

[25] Y. Liu, R. Hu, J.S. Li, H.C. Kou, H.W. Li, H. Chang, H.Z. Fu, Deformation characteristics of as-received Haynes 230 nickel base superalloy, Mater. Sci. Eng. A 497 (2008) 283-289.

[26] Z.N. Bi, M.C. Zhang, J.X. Dong, K.J. Luo, J. Wang, A new prediction model of steady state stress based on the influence of the chemical composition for nickel-base superalloys, Mater. Sci. Eng. A 527 (2010) 4373-4382.

[27] V.V. Balasubrahmanyam, Y. Prasad, Deformation behaviour of beta titanium alloy Ti-10V-4.5Fe-1.5 Al in hot upset forging, Mater. Sci. Eng. A 336 (2002) 150-158.

[28] Y. Wang, W.Z. Shao, L. Zhen, L. Yang, X.M. Zhang, Flow behavior and microstructures of superalloy 718 during high temperature deformation, Mater. Sci. Eng. A 497 (2008) 479-486.

[29] J. Wang, J. Dong, M. Zhang, X. Xie, Hot working characteristics of nickel-base superalloy $740 \mathrm{H}$ during compression, Mater. Sci. Eng. A 566 (2013) 61-70.

[30] R.L. Goetz, S.L. Semiatin, The adiabatic correction factor for deformation heating during the 
1

2

3

4

5

6

7

8

9

10

11

12

13

14

15

16

17

18

19

20

21

22

23

24

25

26

27

28

29

30

31

32

33

34

35

36

37

38

39

40

41

42

43

44

45

46

47

48

49

50

51

52

53

54

55

56

57

58

59

60

uniaxial compression test, J. Mater. Eng. Perform. 10 (2001) 710-717.

[31] K. Song, M. Aindow, Grain growth and particle pinning in a model Ni-based superalloy, Mater. Sci. Eng. A 479 (2008) 365-372. 


\section{Tables}

Table1 Experimental and calculated activation energy of superalloys[26].

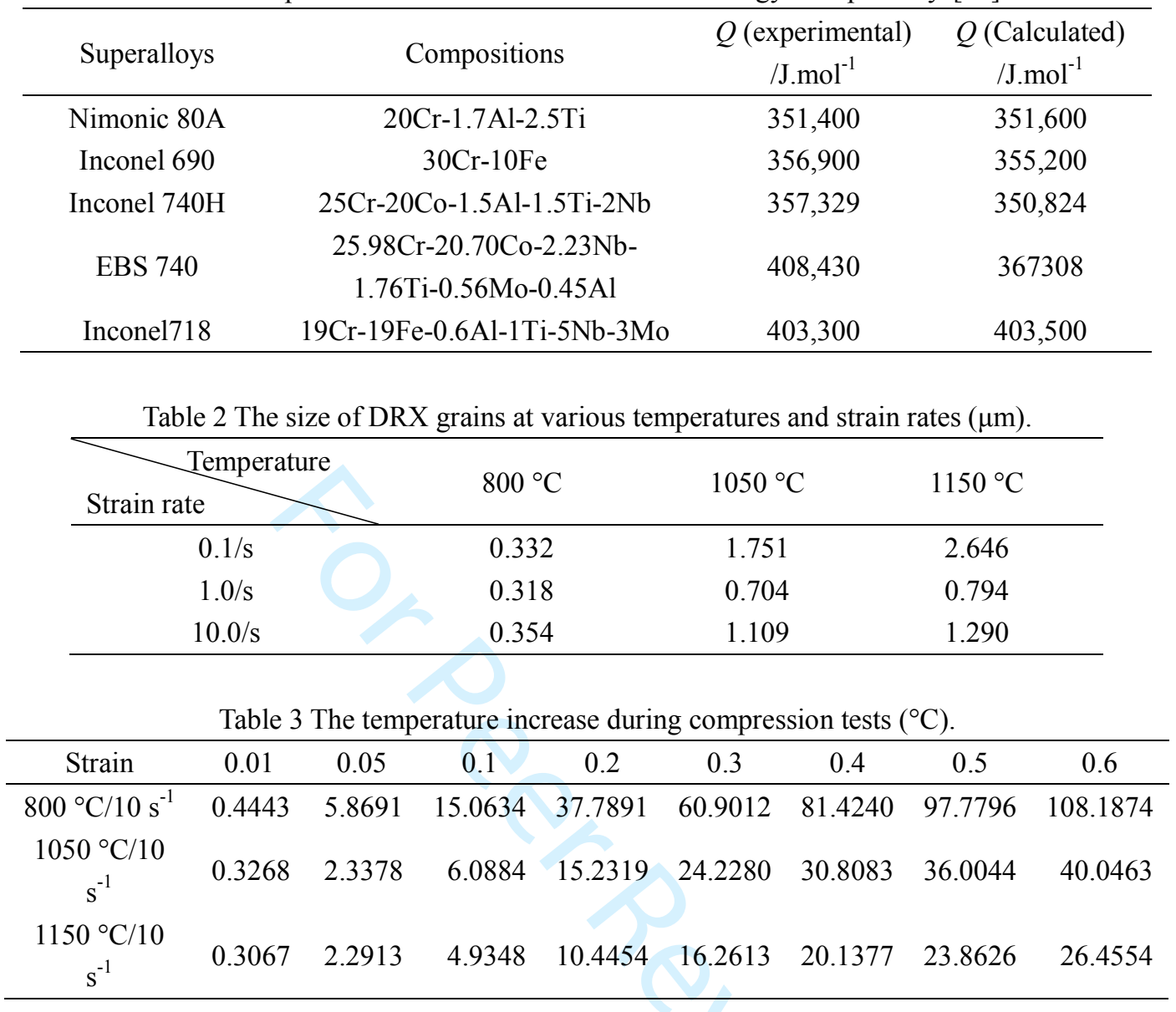




\section{Figure Captions}

Fig. 1. Optical and SEM micrographs of the aged EBS 740 superalloy.

Fig. 2. Shear stress caused by different mechanisms: (a) WCD, SCD, and Orowan mechanism with certain volume fraction of $\gamma^{\prime}$ precipitates; (b) and (c) are WCD shearing and modulus hardening mechanism in relation with the radius and volume fraction of $\gamma^{\prime}$ precipitates.

Fig. 3. The stress-strain curves of EBS 740 superalloy deformed with various strain rates and temperatures.

Fig.4. The variation of strain rate sensitivity exponent with deformation temperatures at the strain of 0.5 (a), and with strain at the temperatures of $538^{\circ} \mathrm{C}$ and $1050^{\circ} \mathrm{C}$ (b).

Fig. 5. Variation of the strain hardening exponent with strain at the temperature of $649^{\circ} \mathrm{C}$ (a), and $1050^{\circ} \mathrm{C}(\mathrm{b})$.

Fig. 6. The relationship between the $\ln \varepsilon$ and $\sigma_{p} / \ln \sigma_{p}$ at various temperatures.

Fig. 7. Relationship between the peak stress and compression parameters.

Fig. 8. The optical microstructures of EBS 740 superalloy deformed at various temperatures and strain rates: (a) $800{ }^{\circ} \mathrm{C}, 0.1 / \mathrm{s}$; (b) $1050{ }^{\circ} \mathrm{C}, 0.1 / \mathrm{s}$; (c) $1150{ }^{\circ} \mathrm{C}, 0.1 / \mathrm{s}$; (d) $800{ }^{\circ} \mathrm{C}, 1 / \mathrm{s}$; (e) $1050{ }^{\circ} \mathrm{C}$, $1 / \mathrm{s}$; (f) $1150{ }^{\circ} \mathrm{C}, 1 / \mathrm{s}$; (g) $800{ }^{\circ} \mathrm{C}, 10 / \mathrm{s}$; (h) $1050{ }^{\circ} \mathrm{C}, 10 / \mathrm{s}$; (i) $1150{ }^{\circ} \mathrm{C}, 10 / \mathrm{s}$.

Fig. 9. Relationship between DRX grain size and hot working parameters: (a) strain rate of $0.1 / \mathrm{s}$, (b) strain rate larger than $1 / \mathrm{s}$.

Fig. 10. Gaussian fitting results of EBS 740 superalloys deformed at $1050{ }^{\circ} \mathrm{C}$ and $1150{ }^{\circ} \mathrm{C}$ at various strain rates.

Fig. 11. The TEM microstructures of EBS 740 superalloy before and after deformation at $1050{ }^{\circ} \mathrm{C}$ with strain rate of $10 / \mathrm{s}$. 
Figures in the manuscript

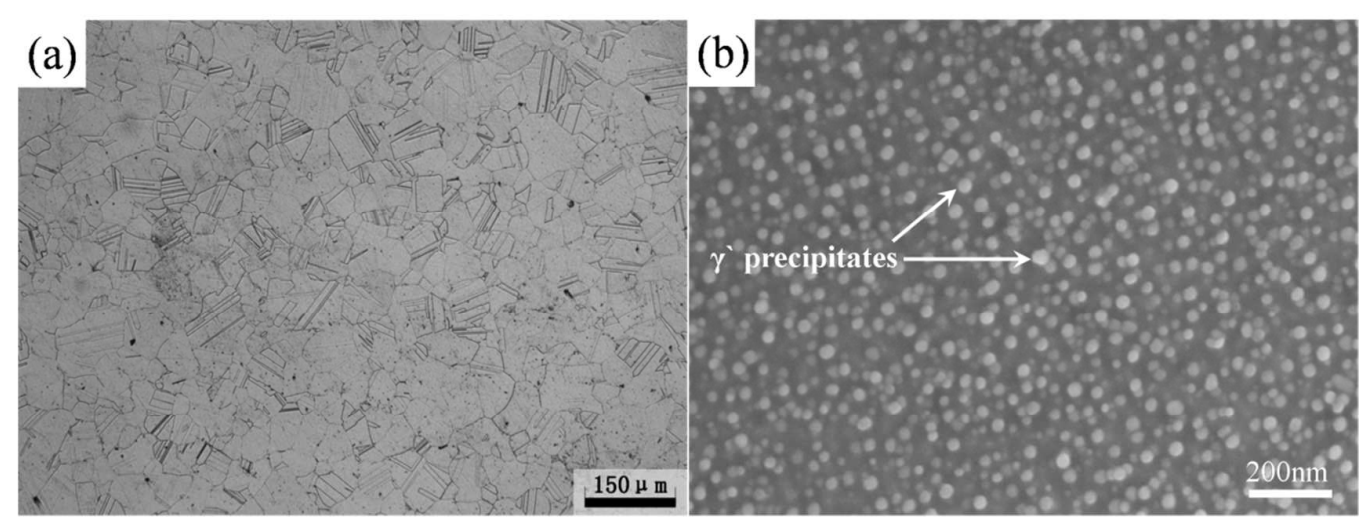

Fig. 1. Optical and SEM micrographs of the aged EBS 740 superalloy. 

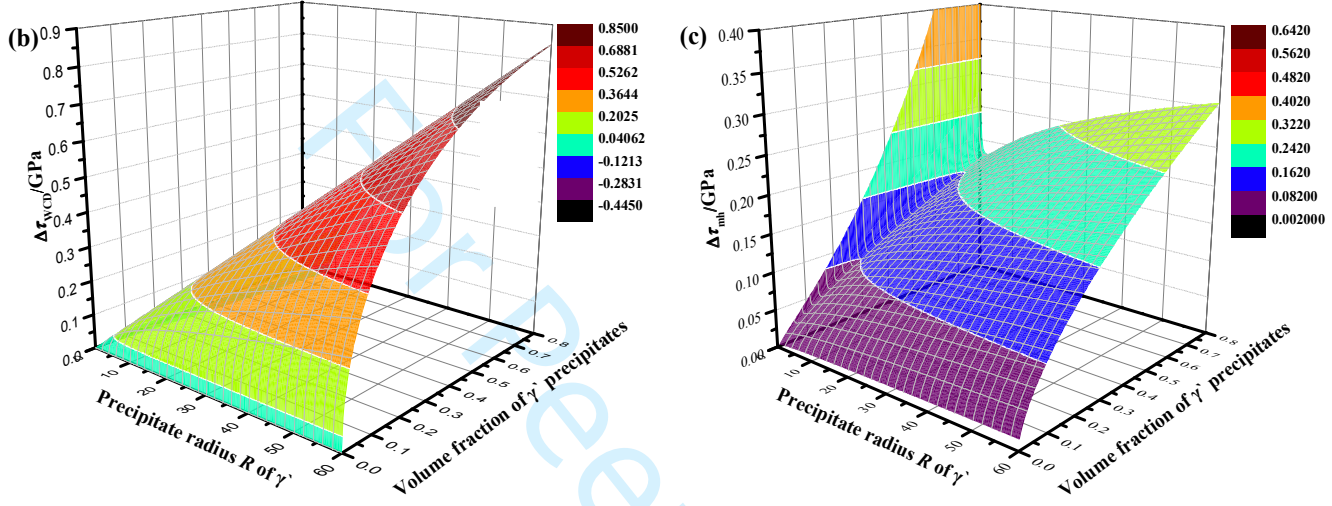

Fig. 2. Shear stress caused by different mechanisms: (a) WCD, SCD, and Orowan mechanism with certain volume fraction of $\gamma^{\prime}$ precipitates; (b) and (c) are WCD shearing and modulus hardening mechanism in relation with the radius and volume fraction of $\gamma^{\prime}$ precipitates. 

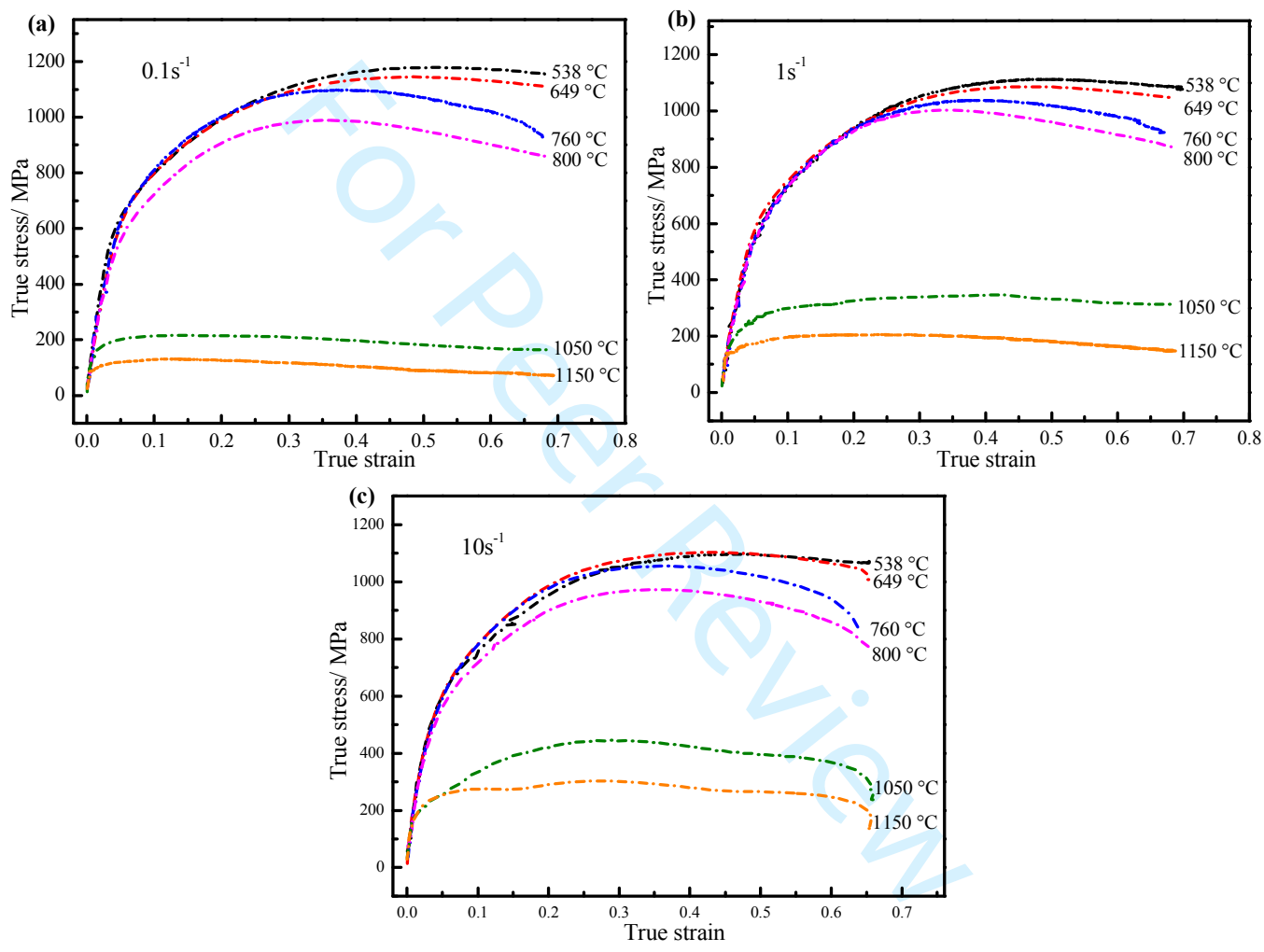

Fig. 3. The stress-strain curves of EBS 740 superalloy deformed with various strain rates and temperatures. 

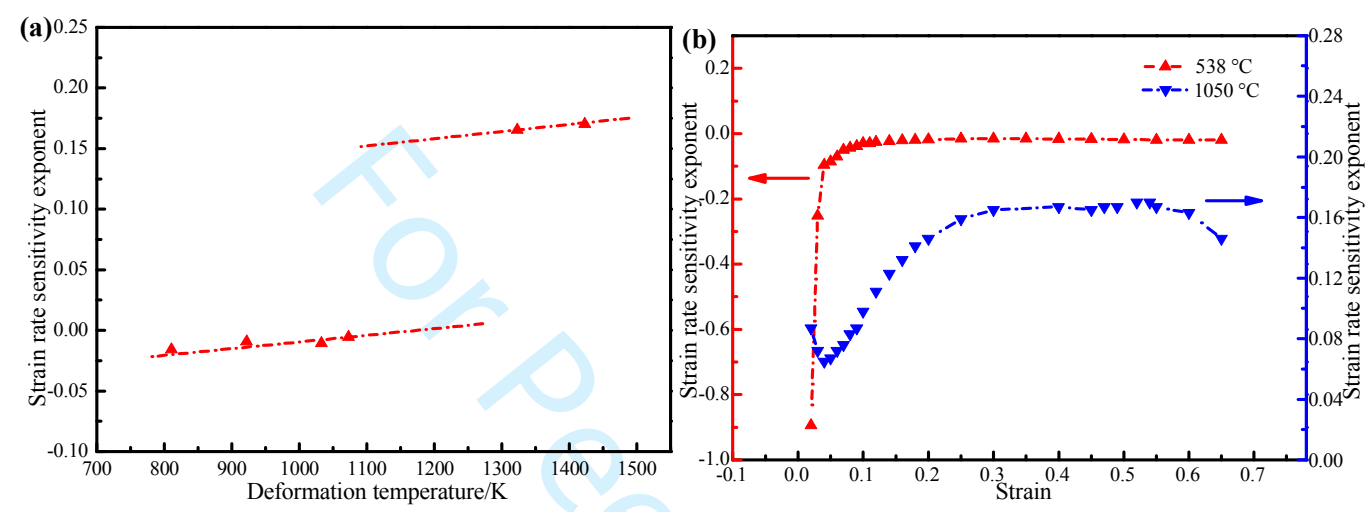

Fig.4. The variation of strain rate sensitivity exponent with deformation temperatures at the strain of 0.5 (a), and with strain at the temperatures of $538^{\circ} \mathrm{C}$ and $1050^{\circ} \mathrm{C}$ (b). 

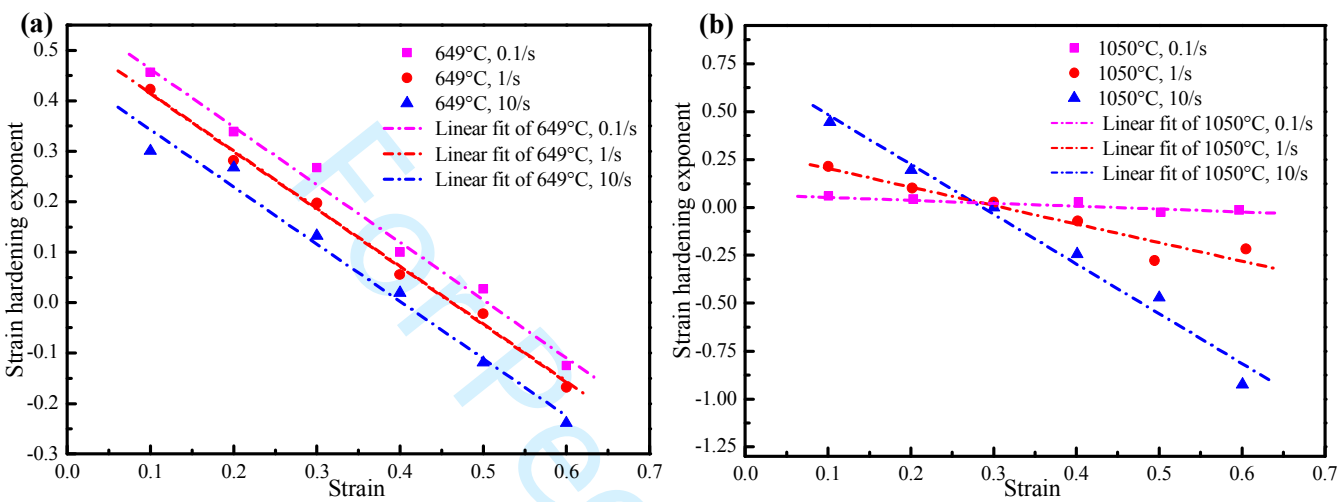

Fig. 5. Variation of the strain hardening exponent with strain at the temperature of $649^{\circ} \mathrm{C}$ (a), and $1050^{\circ} \mathrm{C}(\mathrm{b})$. 

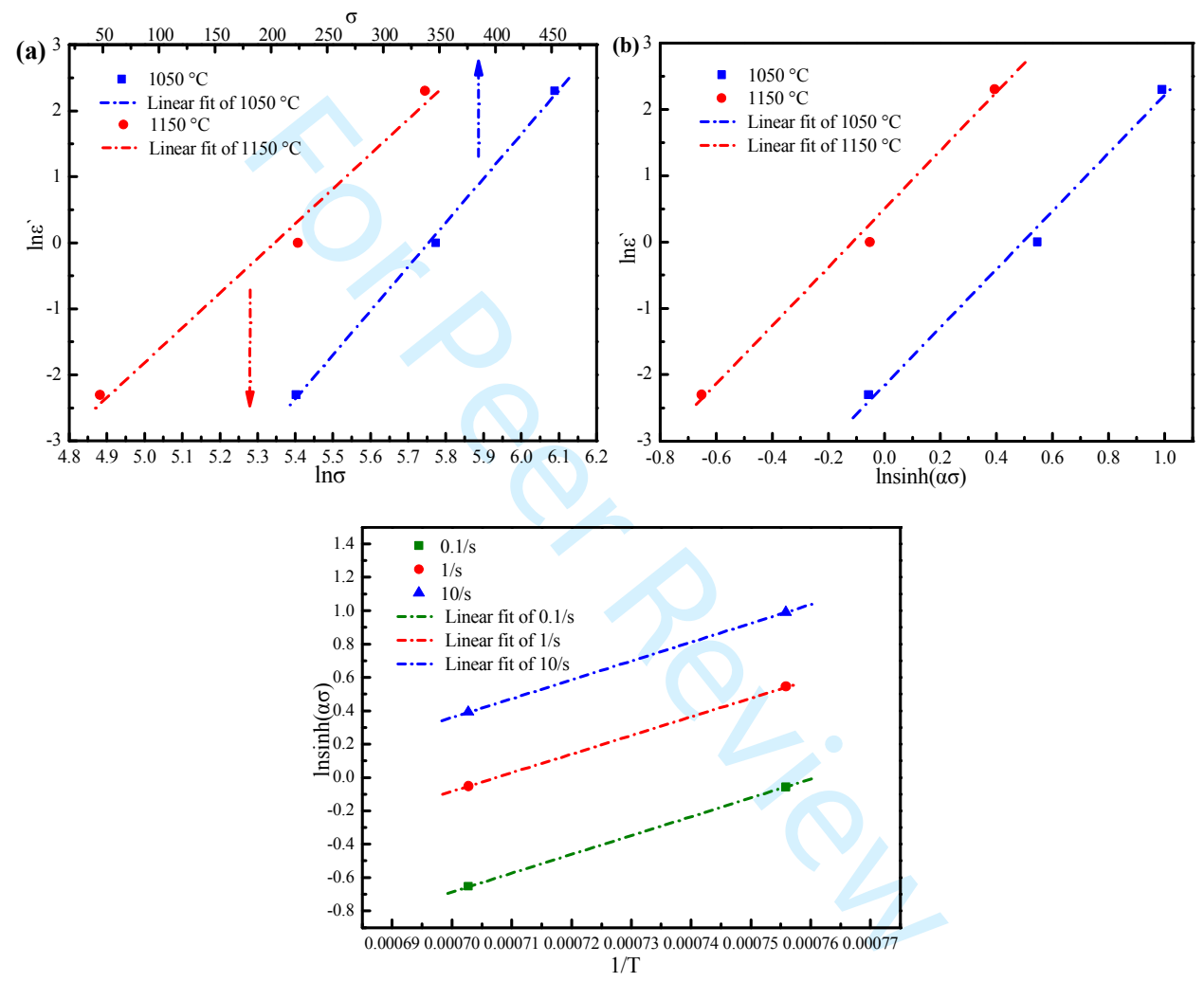

Fig. 6. The relationship between the $\ln \dot{\varepsilon}$ and $\sigma_{p} / \ln \sigma_{p}$ at various temperatures. 

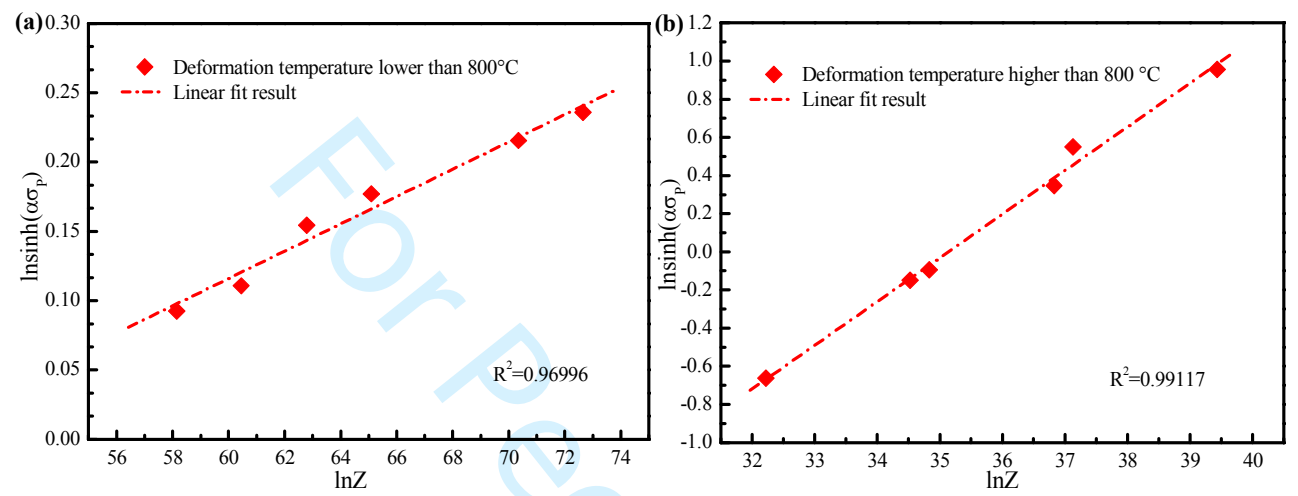

Fig. 7. Relationship between the peak stress and compression parameters. 

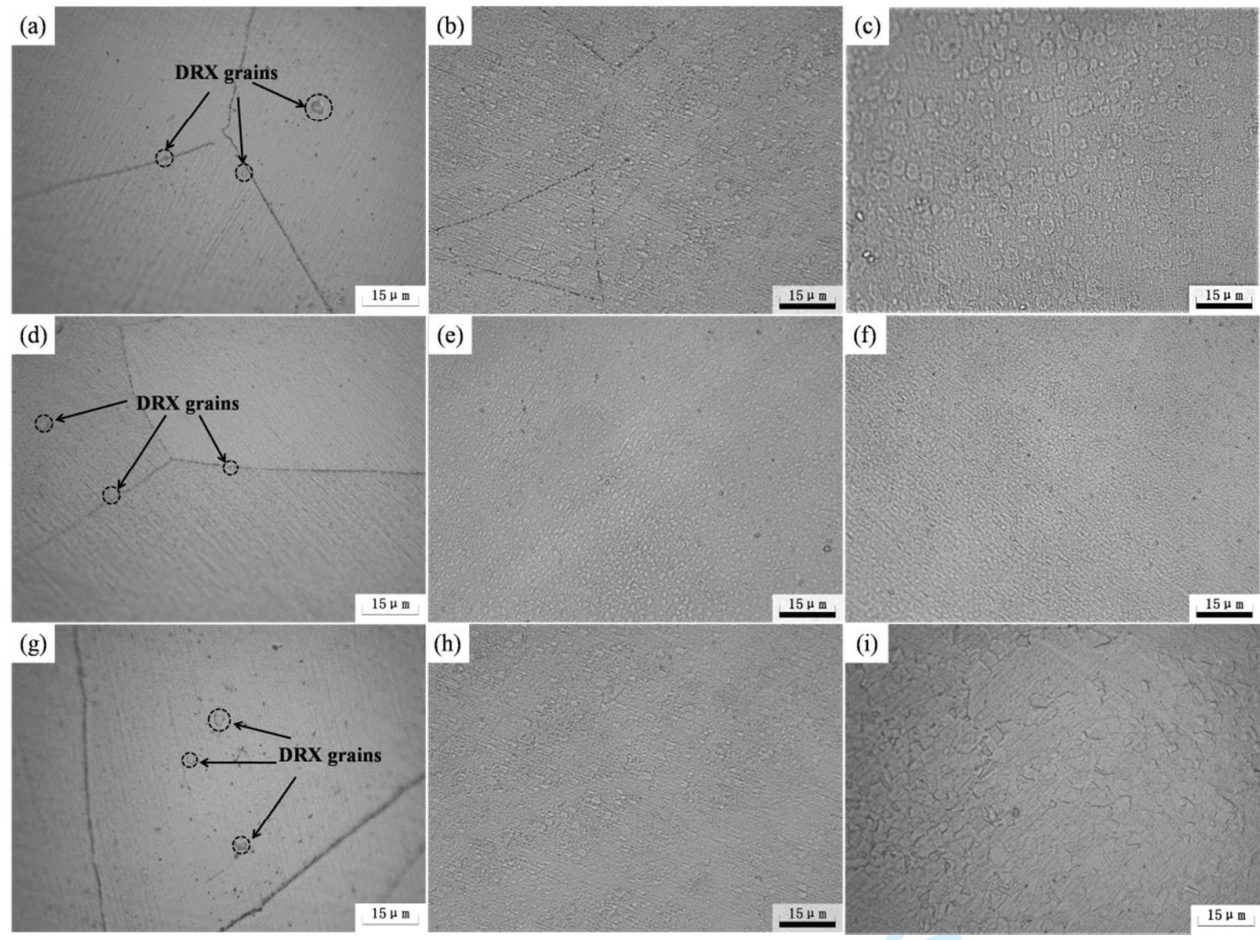

(i)

Fig. 8. The optical microstructures of EBS 740 superalloy deformed at various temperatures and strain rates: (a) $800{ }^{\circ} \mathrm{C}, 0.1 / \mathrm{s}$; (b) $1050{ }^{\circ} \mathrm{C}, 0.1 / \mathrm{s}$; (c) $1150{ }^{\circ} \mathrm{C}, 0.1 / \mathrm{s}$; (d) $800{ }^{\circ} \mathrm{C}, 1 / \mathrm{s}$; (e) $1050{ }^{\circ} \mathrm{C}$, $1 / \mathrm{s}$; (f) $1150{ }^{\circ} \mathrm{C}, 1 / \mathrm{s}$; (g) $800{ }^{\circ} \mathrm{C}, 10 / \mathrm{s}$; (h) $1050{ }^{\circ} \mathrm{C}, 10 / \mathrm{s}$; (i) $1150{ }^{\circ} \mathrm{C}, 10 / \mathrm{s}$. 

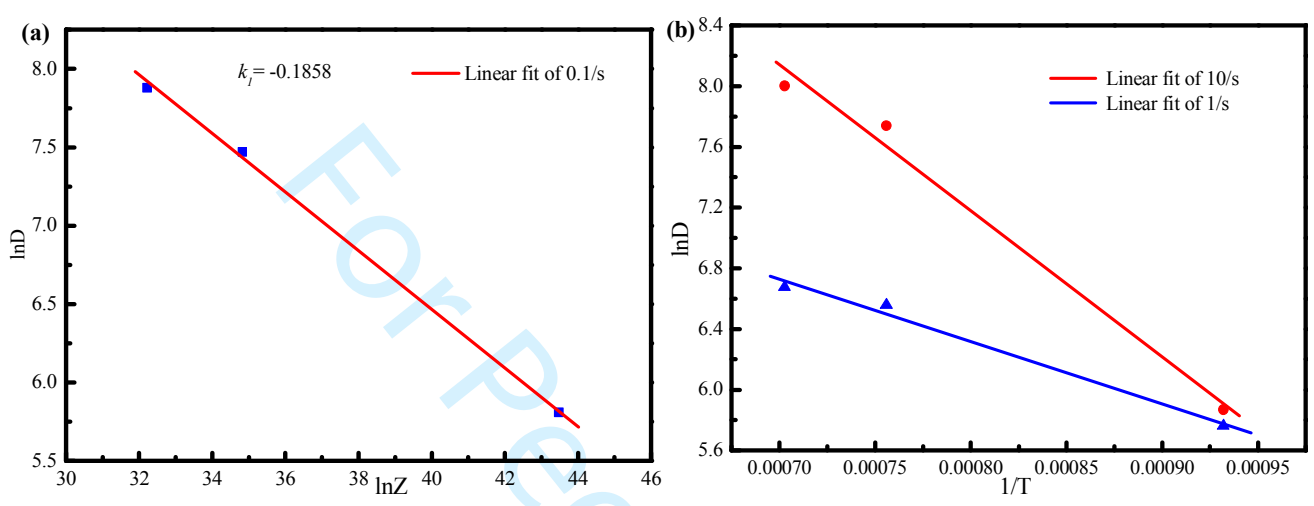

Fig. 9. Relationship between DRX grain size and hot working parameters: (a) strain rate of $0.1 / \mathrm{s}$, (b) strain rate larger than $1 / \mathrm{s}$. 

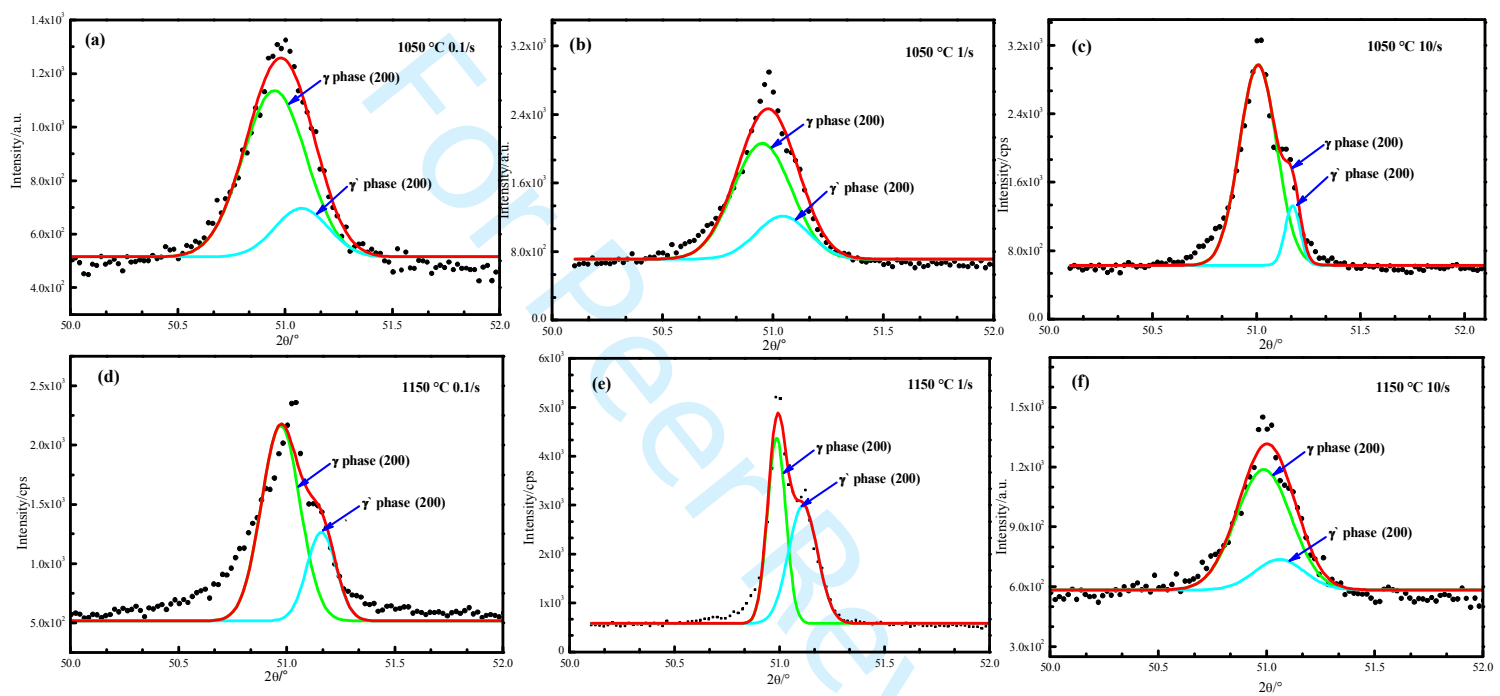

Fig. 10. Gaussian fitting results of EBS 740 superalloys deformed at $1050{ }^{\circ} \mathrm{C}$ and $1150{ }^{\circ} \mathrm{C}$ at various strain rates. 


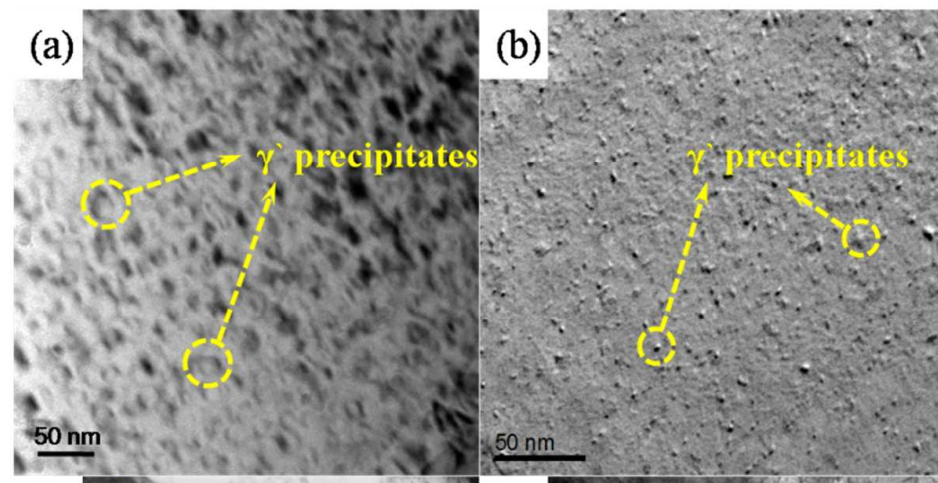

(c)

(d)

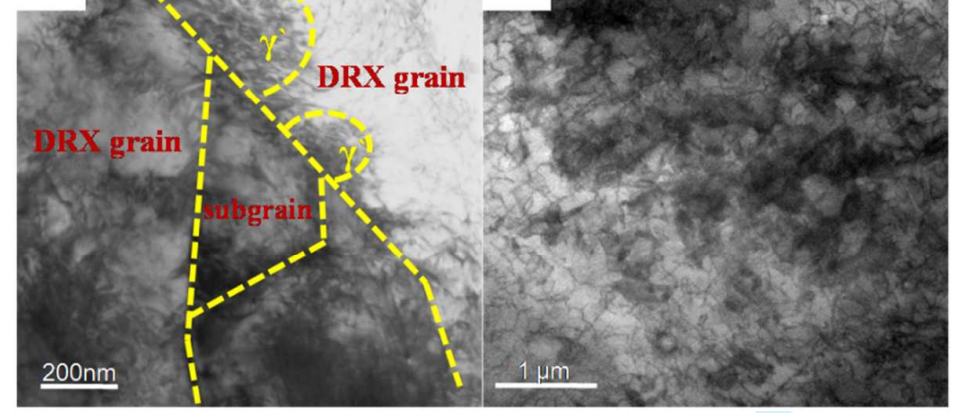

Fig. 11. The TEM microstructures of EBS 740 superalloy before and after deformation at $1050{ }^{\circ} \mathrm{C}$ with strain rate of $10 / \mathrm{s}$. 